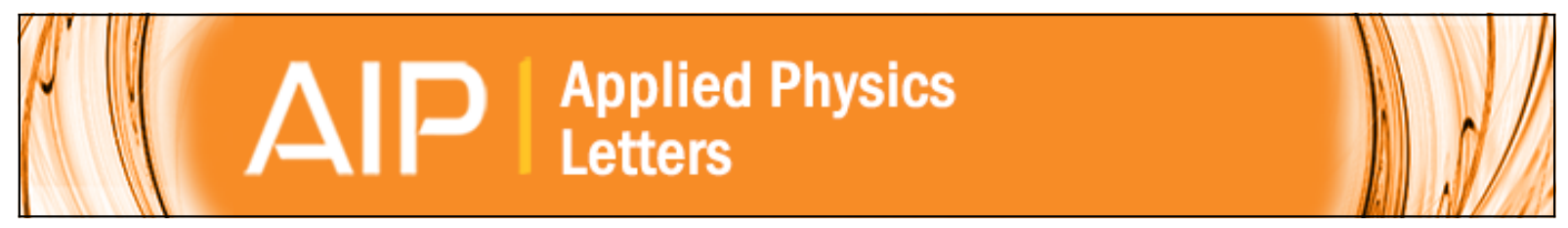

\title{
DNA-Ormocer based biocomposite for fabrication of photonic structures
}

Preeti Gupta, Przemyslaw P. Markowicz, Koichi Baba, James O’Reilly, Marek Samoc, Paras N. Prasad, and James G. Grote

Citation: Applied Physics Letters 88, 213109 (2006); doi: 10.1063/1.2204648

View online: http://dx.doi.org/10.1063/1.2204648

View Table of Contents: http://scitation.aip.org/content/aip/journal/apl/88/21?ver=pdfcov

Published by the AIP Publishing

\section{Articles you may be interested in}

Low threshold amplified spontaneous emission from dye-doped DNA biopolymer

J. Appl. Phys. 111, 113107 (2012); 10.1063/1.4728218

Dual exposure, two-photon, conformal phase mask lithography for three dimensional silicon inverse woodpile photonic crystals

J. Vac. Sci. Technol. B 28, 783 (2010); 10.1116/1.3456181

Three dimensional silicon photonic crystals fabricated by two photon phase mask lithography

Appl. Phys. Lett. 94, 011101 (2009); 10.1063/1.3036955

Fabrication of large area two- and three-dimensional polymer photonic crystals using single refracting prism holographic lithography

Appl. Phys. Lett. 86, 241102 (2005); 10.1063/1.1947369

Fabrication of three-dimensional polymer photonic crystal structures using single diffraction element interference lithography

Appl. Phys. Lett. 82, 1667 (2003); 10.1063/1.1560860

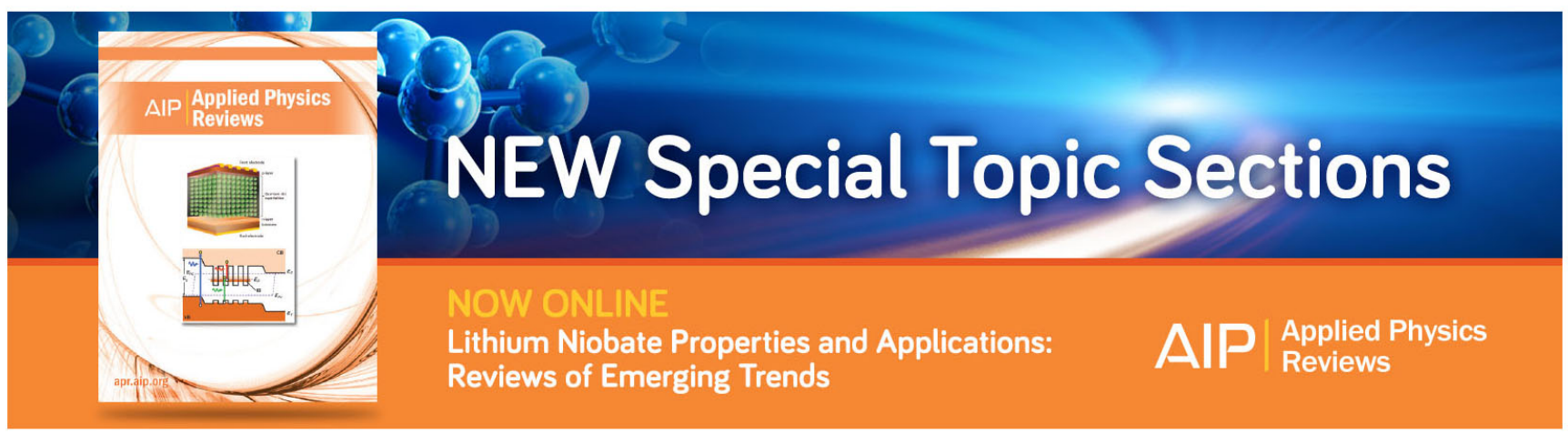




\title{
DNA-Ormocer based biocomposite for fabrication of photonic structures
}

\author{
Preeti Gupta, Przemyslaw P. Markowicz, ${ }^{\text {a) }}$ Koichi Baba, James O’Reilly, \\ Marek Samoc, and Paras N. Prasad \\ The Institute for Lasers, Photonics and Biophotonics, Departments of Chemistry and Physics, University at \\ Buffalo, State University of New York, Buffalo, New York 14260 \\ James G. Grote \\ U.S. Air Force Research Laboratory, Wright-Patterson Air Force Base, Ohio 45433-7707
}

(Received 8 November 2005; accepted 4 April 2006; published online 23 May 2006)

\begin{abstract}
We report microfabrication of high quality photonic structures such as two-dimensional photonic crystals and beam splitters from a high DNA load, photosensitive Ormocer nanocomposite. This nanocomposite combines the high dye loading capacity of DNA with the photopatternability and hardness of the Ormocer. The fabrication is performed with the two-photon lithography method. Detailed studies of the deoxyribonucleic acid distribution in the fabricated structures are conducted with Raman microscopy. We also demonstrate that the deoxyribonucleic acid based nanocomposite films cast on glass substrates are of high enough quality to support amplified spontaneous emission from dyes intercalated in the deoxyribonucleic acid. (C) 2006 American Institute of Physics.
\end{abstract}

[DOI: $10.1063 / 1.2204648]$

Deoxyribonucleic acid (DNA) is one of the most important polymers occurring in nature. It possesses unique properties derived from its double-helix structure. Among these properties, ones that make DNA molecules attractive as components of materials for applications in photonic industry are possibility of high number density loading of appropriate dyes (e.g., by intercalation), low optical losses of DNAbased materials, and specific optical properties due to chirality of the DNA helix. These attractive features have lead to the emergence of the new area of DNA photonics. ${ }^{1-4}$ Thus far, DNA has been used for the fabrication of thin-film waveguide lasers. ${ }^{1,2}$ In this case, amplified spontaneous emission from a dye doped DNA complex was achieved after illumination with a pulsed laser. Use of DNA-based materials as cladding layers in electro-optic devices has also recently been demonstrated. ${ }^{3}$ There were even attempts to fabricate chemical sensors based on a DNA film. ${ }^{4}$ However, to further exploit DNA's properties in photonic industry, it will be very useful to have a technology which will enable fabrication of optoelectronic devices of micrometer resolution.

In this letter, we demonstrate microfabrication of photonic structures using two-photon lithography in a DNAORMOCER $®$ nanocomposite which contains equal amounts of a DNA-surfactant complex and the ORMOCER ${ }^{\circledR}$ resin. We illustrate amplified spontaneous emission from a Rhodamine-6G doped DNA-ORMOCER ${ }^{\circledR}$ nanocomposite film after polymerization of a specific area to show that the film is still of high quality after completion of the fabrication process. Furthermore, incorporation of ORMOCER ${ }^{\circledR}$ provides mechanical strength, and thus better hardness (scratch resistance) as compared to otherwise soft and readily scratchable DNA film.

ORMOCER ${ }^{\circledR}$ (Fraunhofer Institut Silicatforschung, Germany) is an inorganic-organic hybrid, high optical quality resin thermally stable to $275^{\circ} \mathrm{C}^{5}$. This material exhibits good optical and dielectric properties in the near infrared and visible regions. It also possesses appreciable mechanical

\footnotetext{
${ }^{a)}$ Electronic mail: ppm@nsm.buffalo.edu
}

properties and is soluble in common solvents such as methanol, acetone, chloroform, etc.

Natural deoxyribonucleic acid, on the contrary, is only water soluble and is a soft material, not very suitable for the fabrication of optoelectronic device structures. However, the physical properties of the DNA can be modified by binding surfactants to it. This process makes the DNA soluble in organic solvents such as ethanol and chloroform which are also common solvents used for lithography. The DNAsurfactant complex in our studies was prepared by mixing aqueous solutions of DNA and hexadecyltrimethylammonium chloride. Then, $0.05 \mathrm{~g}$ of the DNA-surfactant complex was dissolved in $0.25 \mathrm{ml}$ of ethanol and the solution was sonicated for an hour. Simultaneously, the CIBA Darocur 4265 liquid UV photoinitiator was added to the monomer ORMOCER $®$, with the ratio of the photoinitiator to ORMOCER ${ }^{\circledR}$ being 1:2. ORMOCER $®$ mixed with the photoinitiator was dissolved in ethanol. The concentration of ORMOCER ${ }^{\circledR}$ was the same as that of the DNA-surfactant complex. These two solutions, namely, the DNA-surfactant complex in ethanol and ORMOCER $®$ with the photoinitiator in ethanol, were mixed together and sonicated for an hour. The prepared solution was left standing overnight at room temperature to dissipate the air bubbles in order to get a homogeneous and high optical quality film.

The mechanical and the thermal properties of such films were studied to determine the usefulness of the DNA nanocomposite for applications in optical devices. Thin films of DNA, DNA-ORMOCER $®$, and ORMOCER ${ }^{\circledR}$ were spin coated at $1000 \mathrm{rpm}$ on glass slides. A simple method to characterize the hardness of films and coatings is pencil hardness which is described in ASTM D33636. ${ }^{6}$ The ASTM method was carried out using Koh-i-Noor pencils ranging from $\mathrm{B}$ (softest), to HB, F, H, 2H, and 4H(hardest). The DNA films were scratched by the B pencil which is comparable to a soft polyethylene film. The DNA/ORMOCER ${ }^{\circledR}$ films, in contrast, were scratched by an $\mathrm{F}$ pencil which is comparable to a polycarbonate film, a tough polymer used in ophthalmic lenses. The ORMOCER $®$ films were scratched by a $2 \mathrm{H}$ pen- 


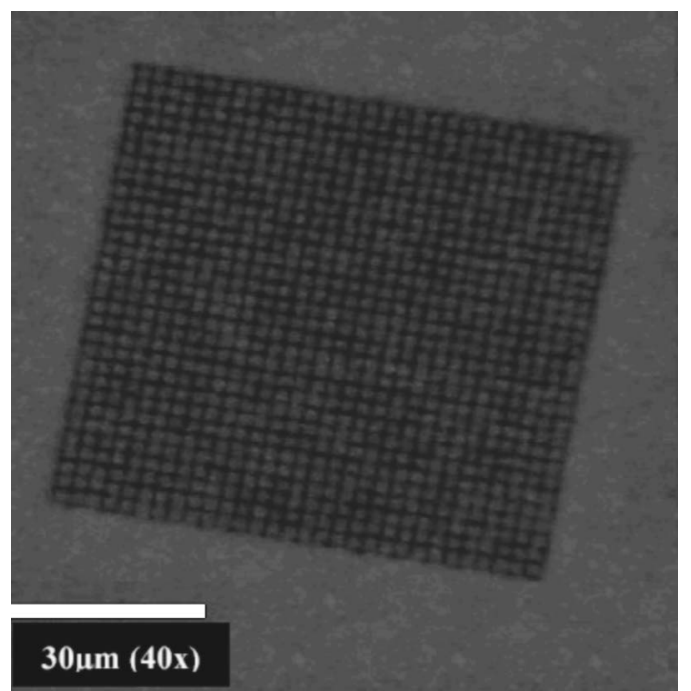

FIG. 1. A $90 \times 90 \mu \mathrm{m}^{2}$ two-dimensional periodic structure fabricated in a DNA-Ormocer nanocomposite using two-photon lithography and imaged in reflection mode using a confocal microscope.

cil which is comparable to cross-linked epoxies. These studies show that the DNA-ORMOCER $®$ nanocomposite is significantly harder than the pure DNA-surfactant material.

The initial objective of our differential scanning calorimetry (DSC) study was to compare the thermal properties, in particular, the glass transition temperature $\left(T_{g}\right)$, of DNA, 1:1 DNA-ORMOCER®, and ORMOCER®. A $T_{g}$ for DNA around $60{ }^{\circ} \mathrm{C}$ was expected from the published literature. ${ }^{7}$ Our DNA samples with the surfactant showed a broad melting peak, $35-65{ }^{\circ} \mathrm{C}$, with a heat of melting of $99 \mathrm{~J} / \mathrm{g}$, characteristic of crystalline order. The broadness of the melting peak suggests heterogeneity in the sample which could be due to variation in the moisture content or morphology of the crystals. The second heating of this sample to a higher temperature of $200{ }^{\circ} \mathrm{C}$ gave a flat curve with no melting or glass transition temperature and a large endothermic peak at $120-140{ }^{\circ} \mathrm{C}$ which could be due to changes in the double helical structure. DSC studies of 1:1 DNA-ORMOCER ${ }^{\circledR}$ revealed no significant transitions from 20 to $200{ }^{\circ} \mathrm{C}$. Minor endothermic changes, which occur at $130-160{ }^{\circ} \mathrm{C}$, may be due to DNA. However, the magnitude of change does not vary linearly with respect to the proportions of the DNA and the ORMOCER ${ }^{\circledR}$. This may suggest that the DNA in the final cross-linked ORMOCER ${ }^{\circledR}$ may be denatured (nonhelical). We are planning to verify this hypothesis by other methods. Photocross-linked ORMOCER® does not show any changes up to $300{ }^{\circ} \mathrm{C}$. The high level of cross-linking makes the observation of $T_{g}$ difficult for temperatures higher than $300{ }^{\circ} \mathrm{C}$

Overall, a lack of thermal transitions of significant magnitude between 60 and $300{ }^{\circ} \mathrm{C}$ suggests that the DNAsurfactant complex and the ORMOCER ${ }^{\circledR}$ are not thermodynamically miscible (compatible) but are phase separated on nanoscale. ${ }^{8}$ Our studies also reveal that DNA in the DNAORMOCER $®$ nanocomposite has comparable thermal properties $\left(T_{g}\right)$ to those of DNA. However, its mobility is restricted because the DNA molecules are encapsulated by the ORMOCER® structure.

A femtosecond mode-locked, Ti:sapphire laser with $80 \mathrm{MHz}$ repetition rate was used as the excitation source for the two-photon polymerization process. The laser provides a

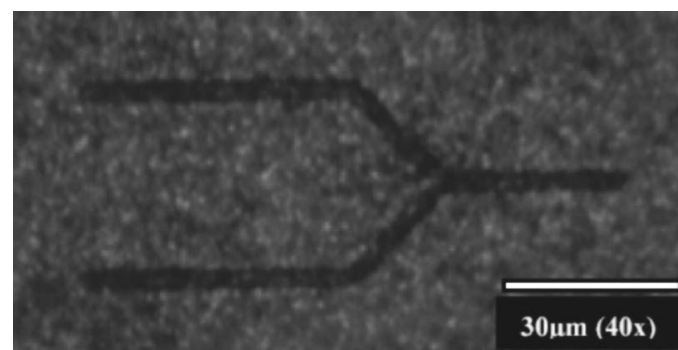

FIG. 2. A $90 \times 45 \mu \mathrm{m}^{2}$ beam splitter fabricated in a DNA-Ormocer nanocomposite and imaged in reflection mode using a confocal microscope.

wavelength of $790 \mathrm{~nm}$ and a pulse width of $300 \mathrm{fs}$, with an average power of $9 \mathrm{~mW}$ under the objective. The sample was mounted on a computer controlled piezoelectrically driven $X Y Z$ stage. Since the polymerization of the resin occurs only if the intensity of the laser beam exceeds a certain threshold value, the laser beam was tightly focused using a $40 \times$ objective with a numerical aperture of 0.6. A two-dimensional periodic structure (photonic crystal) was written with a speed of $30 \mu \mathrm{m} / \mathrm{s}$. For developing, the sample was washed for a few seconds with a mixture of ethanol and 4-methyl-2pentanone to remove the ORMOCER ${ }^{\circledR}$ and the DNAsurfactant in the unpolymerized regions. Figures 1 and 2 show confocal reflection mode microscopic images of two different structures, created from the DNA/ORMOCER ${ }^{\circledR}$ nanocomposite using two-photon lithography. The first figure represents a two-dimensional (2D) periodic structure (photonic crystal) and the second is a $1 \times 2$ beam splitter. The lines are $3 \mu \mathrm{m}$ apart in the case of the periodic structure.

$\mathrm{An} \mathrm{Ar}^{+}$laser operating at a wavelength of $488 \mathrm{~nm}$ was used to record Raman signals from the sample in order to study its quality. As can be seen by the confocal Raman image in Fig. 3, a Raman signal at $2990 \mathrm{~cm}^{-1}$, corresponding to the surfactant, is observed only from the polymerized regions. This image proves that DNA was removed on development from the unexposed regions.

In order to verify the optical quality of the film after the entire fabrication process was completed, we generated amplified spontaneous emission (ASE) from the sample. For this purpose, we used Rhodamine-6G as an intercalating dye. It is well known that fluorescent dyes such as Rhodamine-

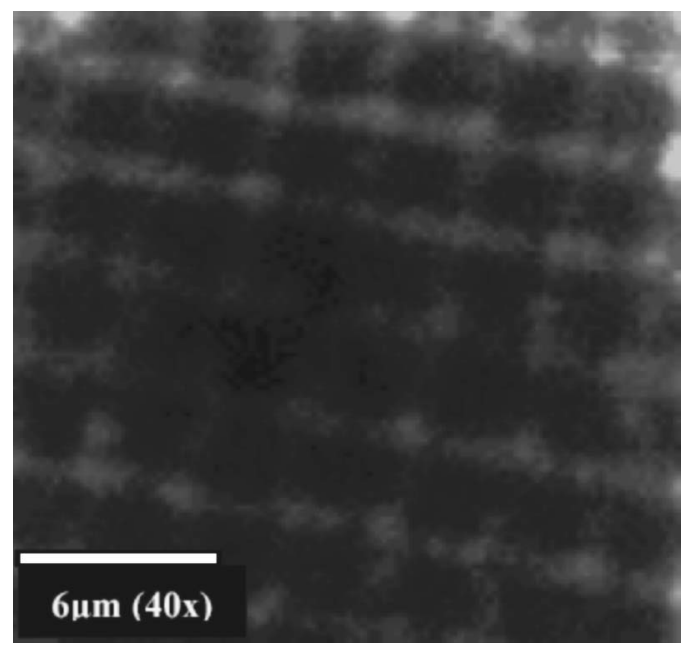

FIG. 3. Vibrational confocal imaging using a Raman band corresponding to the surfactant from the periodic structure fabricated in DNA-Ormocer nanocomposite. 


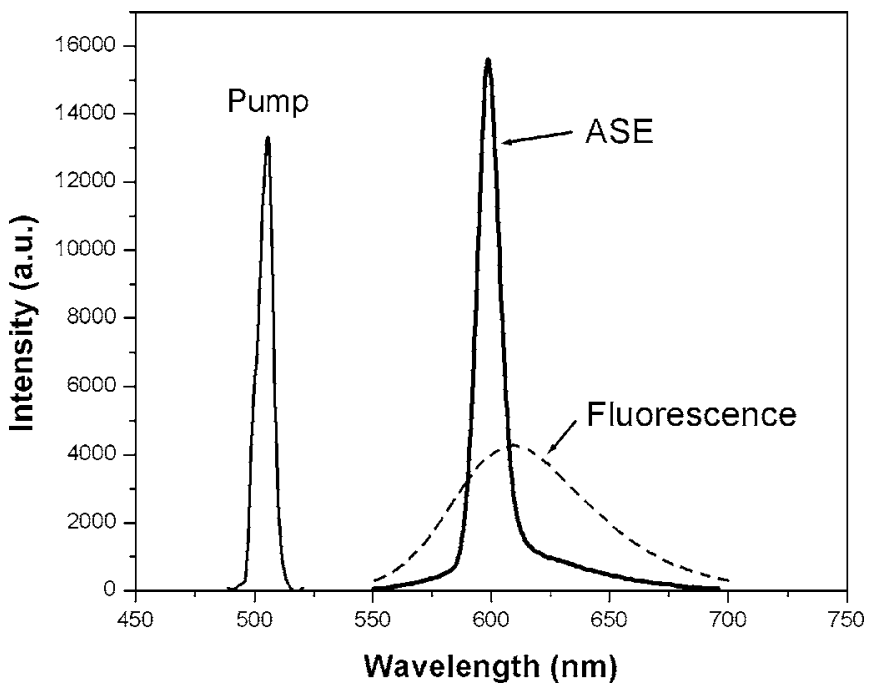

FIG. 4. Fluorescence (dashed curve) and amplified spontaneous emission (solid curve) from a Rhodamine-6G doped DNA-Ormocer nanocomposite film after the completion of the fabrication process.

6G, acridine orange, and ethidium bromide can be intercalated within the helical structure of DNA. ${ }^{9}$ Intercalation occurring as the binding of a single dye molecule to the base pair of the DNA strand isolates the dye molecules from each other and hence prevents their aggregation. As a result, a large amount of the dye can be stacked inside the DNA. The molecular ratio of the DNA base pairs to Rhodamine-6G dye was $25: 1$ in our case. A film of the Rhodamine-6G doped DNA-ORMOCER ${ }^{\circledR}$ nanocomposite was cast on a glass slide, as described earlier. A rectangular area of $1 \mathrm{~cm}^{2}$ was exposed to the UV light and was developed with a mixture of ethanol and 4-methyl-2-pentanone. For the measurement of the emission spectra from this polymerized area, a femtosecond optical parametric amplifier (OPA), pumped by the Ti:sapphire oscillator amplifier system and operating at $1 \mathrm{kHz}$ repetition rate, was used as the excitation source. The wavelength of the OPA was tuned to $\sim 505 \mathrm{~nm}$ which corresponded to the maximum of absorption of Rhodamine- $6 \mathrm{G}$ in the DNA-ORMOCER $®$ nanocomposite. The average power of the laser beam incident on the sample was around $1.30 \mathrm{~mW}$. The laser beam was focused on the sample into a stripe shape with the help of a $f=20 \mathrm{~cm}$ cylindrical lens. The emission was collected from the edge of the sample with the help of a fiber and was recorded by a spectrometer attached to it. Figure 4 shows the emission spectra from the Rhodamine-6G doped DNA-ORMOCER $\AA$ nanocomposite, after polymerization, when pumped at $505 \mathrm{~nm}$. The dashed curve illustrates fluorescence with maximum at $608 \mathrm{~nm}$, observed when pumped at low power. The solid curve shows a much narrow emission spectrum, indicative of ASE with emission peaking at $602 \mathrm{~nm}$, obtained when the pump power increased above a certain threshold. The full width at half miximum (FWHM) was determined to be $12 \mathrm{~nm}$. Moreover, the amplified spontaneous emission was also observable when the film was excited with a wavelength of $400 \mathrm{~nm}$ which lies at the edge of the absorption spectrum of the Rhodamine-6G doped DNA complex. This confirms that the film still exhibits high optical quality after polymerization and developing.

In conclusion, we have presented microfabrication of high quality photonic structures from the DNAORMOCER ${ }^{\circledR}$ photosensitive nanocomposite. The use of ORMOCER $®$ in the nanocomposite increases its mechanical strength and makes it photopatternable. DNA enhances solubility of active dyes in the material and makes it suitable for the fabrication of micrometer size active photonic devices. Thus these nanocomposites combine the merits of both the ORMOCER® and DNA.

This research was supported by a DURINT Grant No. F496200110358 from the Chemistry and Life Sciences Directorate of the Air Force Office of Scientific Research. This work was also supported by the Air Force Research Laboratory, Materials and Manufacturing Directorate (AFRL/ML), the Asian Office of Advanced Research and Development (AOARD), and the Air Force Office of Scientific Research (AFOSR). The authors acknowledge the pioneering work done by Professor Naoya Ogata (CIST) in making salmon DNA available for our BiOFET research. We also thank Dr. Frank K. Hopkins for his help.

${ }^{1}$ Y. Kawabe, L. Wang, S. Horinouchi, and N. Ogata, Adv. Mater. (Weinheim, Ger.) 12, 1281 (2000).

${ }^{2}$ Y. Kawabe, L. Wang, T. Nakamura, and N. Ogata, Appl. Phys. Lett. 81, 1372 (2002).

${ }^{3}$ J. G. Grote, J. A. Hagen, J. S. Zetts, R. L. Nelson, D. E. Diggs, M. O. Stone, P. P. Yaney, E. Heckman, C. Zhang, W. H. Steier, A. K. Y. Jen, L. R. Dalton, N. Ogata, M. J. Curley, S. J. Clarson, and F. K. Hopkins, J. Phys. Chem. B 108, 8584 (2004).

${ }^{4}$ P. P. Yaney, E. M. Heckman, D. E. Diggs, F. K. Hopkins, and J. G. Grote, Proc. SPIE 5724, 224 (2005)

${ }^{5}$ R. Houbertz, L. Froehlich, M. Popall, U. Streppel, P. Dannberg, A. Braeuer, J. Serbin, and B. N. Chichkov, Adv. Eng. Mater. 5, 551 (2003).

${ }^{6}$ ASTM D 3363-00, Standard Test Method for Film Hardness by Pencil Test.

${ }^{7}$ S. L. Lee, P. G. Debenedetti, J. R. Errington, B. A. Pethica, and D. J. Moore, J. Phys. Chem. B 108, 3098 (2004).

${ }^{8}$ K. Aoi, A. Takasu, and M. Okada, Polymer 41, 2847 (2000).

${ }^{9}$ X. Hou, M. Xu, L. Wu, and J. Shen, Colloids Surf., B 41, 181 (2005). 